\title{
Design of a new railway wagon for intermodal transport with the adaptable loading platform
}

\author{
Pavol Št'astniak ${ }^{1, *}$, Pavol Kurčík and Alfréd Pavlík ${ }^{1}$ \\ ${ }^{1}$ University of Žilina, Faculty of Mechanical Engineering, Department of Transport and Handling Machines, Univerzitná 8215/1, 010 26 \\ Žilina, Slovak Republic
}

\begin{abstract}
The aim of the article is to present the structural design of freight railway wagon with variable use of loading space with regard to the safe operation and assessment of the properties by the calculation methods of simulation analysis. Virtual model of wagon was created in a computer program PTC/Creo. After creating the construction, the calculation model of the wagon frame was subjected to the static and dynamic analysis in programs ANSYS and ADAMS/Rail. On the basis of computer aided simulation analysis was optimized the chassis frame of the wagon. This wagon will be able to offer even more capacity and utilize less resources and energy than current wagons for intermodal transport.
\end{abstract}

\section{Introduction}

Indeed nowadays about 1,5 billion $\mathrm{t} / \mathrm{km}$ are transported in Europe by lorry at distances farther than $150 \mathrm{~km}$, conversely only 0,4 billion $\mathrm{t} / \mathrm{km}(20 \%)$ are transported by train, this entails important costs for fossil fuels. In the nearby future when transportation has to be more sustainable it seems quite clear that freight railways will win the mode choice more often [1].

For this to happen though, it is necessary that freight railways, apart from lowering their prices, significantly improve highly increase the quality of transportation. In that sense, quality standards such as reliability, flexibility, availability, cargo security and safety, punctuality, customisation, marketability, traceability, complementary servicing and time for transport among others have to be improved by railways as well.

Hence, rail freight has the challenge to become excellent and to gain in reputation. There are many actions to increase quality in rail freight transport; one of them is the optimisation of the current wagon fleet to improve availability, flexibility, marketability, commercial speed, cargo security and cost. This optimisation has to respond to the actual trends of transport demand and has to be in consonance with the required and feasible infrastructure upgrades.

The basic idea of new wagon is that in the future, longer loading surfaces without interruptions, as well as more capable platforms with higher axle loads and with lower loading heights will be necessary to increase the capacity of the freight railway transportation.

The time schedule is divided to several subtasks as shown in Fig. 1.

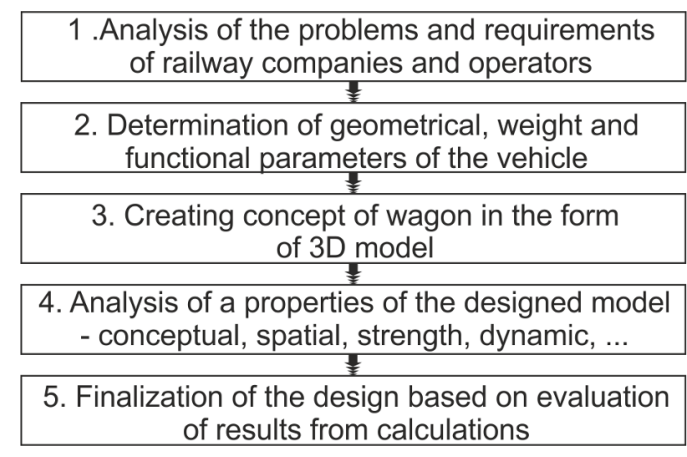

Fig. 1. The time schedule segmented into several subtasks.

\section{Analysis of the problems and requirements of railway operators}

Intermodal continental transports utilize a large amount of unit types (much more than hinterland (sea) transportation) and that increases the amount of possible loading cases for the trains. In that sense, there would be an optimal wagon for each case but this wagon could be sub-optimally utilized for other cases. This variety of cases makes difficult to know which wagon is the optimal for an averaged situation.

Wagons represent an important investment for companies (c.a. $100.000 €$ per wagon) and they should be extensively utilized during their whole life cycle (2530 years) to achieve profitability. For this reason, wagons specialized in one kind of units are usually employed for other unit types even if they are not $100 \%$ efficient at it.

From individual wagons were created four trains, whose maximum length were $500 \mathrm{~m}$ and have been investigated the parameters listed in Fig. 2.

\footnotetext{
*Corresponding author: pavol.stastniak@fstroj.uniza.sk
} 


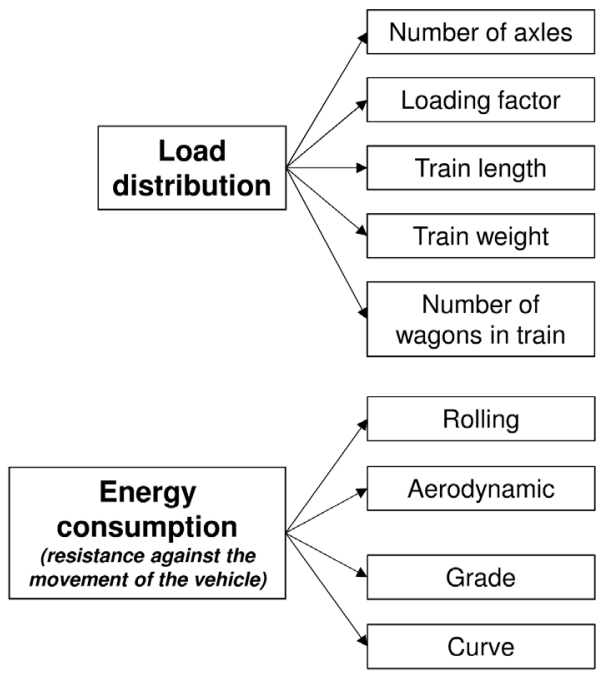

Fig. 2. The time schedule segmented into several subtasks.

Concluding that:

- $106 \mathrm{ft}$ wagon suits optimally the FTL (full truck load, semitrailers) segment and performs quite reasonably in other segments except the pure bulk ones.

- $60 \mathrm{ft}$ wagon is the optimal wagon for the pure bulk segment.

- $80 \mathrm{ft}$ wagon would offer better performance than $106 \mathrm{ft}$ in averaged situations (mainstream shuttles), but it is not recommended for specialized FTL transports, however it performs better than $106 \mathrm{ft}$ wagon in bulk segments.

- $90 \mathrm{ft}$ wagon would offer better performance than $80 \mathrm{ft}$ if in the future the $45 \mathrm{ft}$ unit is widely introduced. since it would enable better utilization of space (loading length) on trains than existing wagon technologies. The $80 \mathrm{ft}$ wagons would be able to transport same of even more amount of units with the fewer axles and the less deadweight. Furthermore, the aerodynamics would improve (fewer gaps between containers, fewer bogies per meter) and the noise emissions would be reduced due fewer axles per train.

Longer loading lengths $85 \mathrm{ft}$ and $90 \mathrm{ft}$ could have an advantage too, but only if the $45 \mathrm{ft}$ unit is widely introduced and if it dominates in intermodal traffics, which is not the actual case. A revision of this issue has to take place in the approximately 5 years.

The strategic procedure would be to design a $80 \mathrm{ft}$ without pocket and try to make it as cheap as possible. By this it could be very competitive in its market segment.

\section{Concept of wagon in the form of 3D model}

The model presents a complete structure of the 4 - axle freight wagon (Fig. 3) for transportation of ISO containers and swap bodies which should meet prescriptions TSI-WAG, valid regulations UIC, agreement on the reciprocal use of freight wagons in international traffic AVV (RIV), recommendations ERRI and norms EN.

Chassis frame (Fig. 4) is welded the steel construction consisting of two side longitudinal beams (in the most of "I" profiles various sections) which through the cross beams create a support frame. On

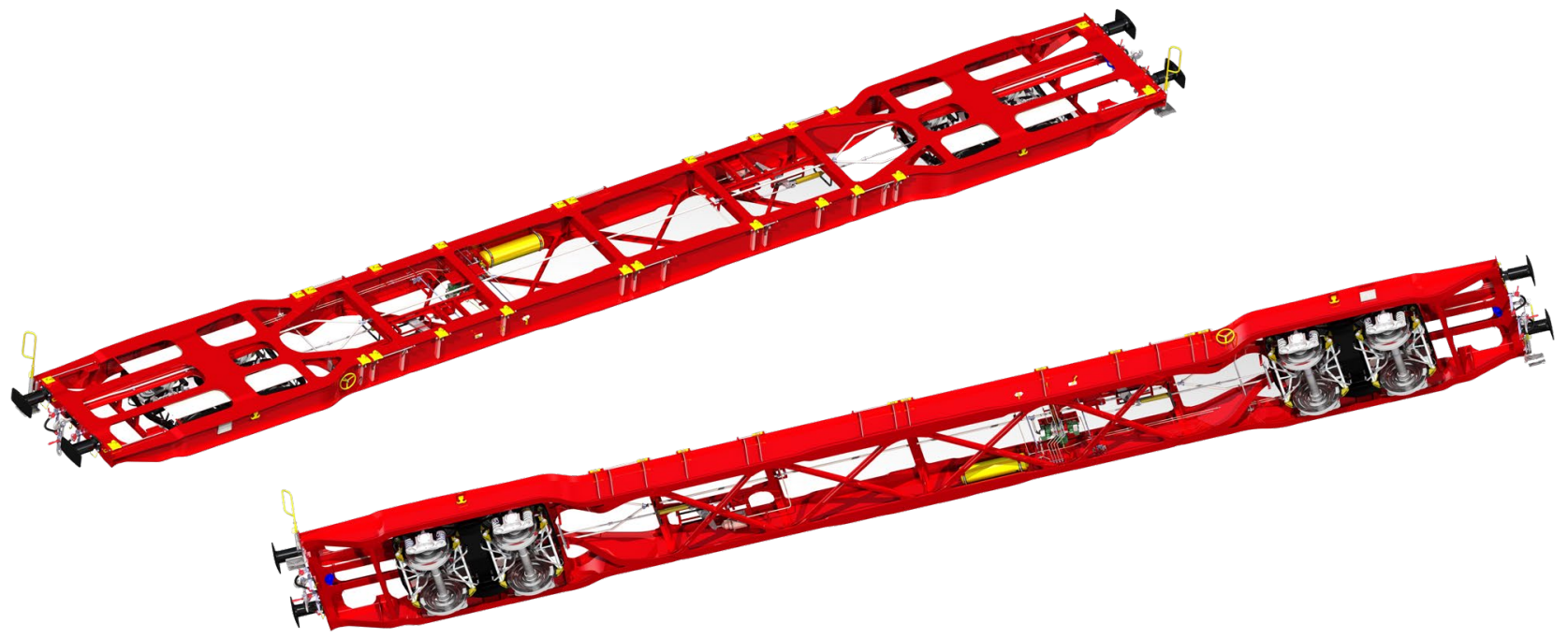

Fig. 3. Realistic image of the wagon by $3 \mathrm{D}$ rendering in program $\mathrm{PTC} / \mathrm{Creo}$.

The results of the capacity simulations have showed that an $80 \mathrm{ft}$ long wagon could lead to an important advantages in efficiency. These advantages would be amplified by averaged cases with mixture of units, for example in the case of a shuttle between the two important continental terminals with an unknown and varying proportion of units.

It could be concluded that the $80 \mathrm{ft}$ wagon would bring about an important gain for continental transports lower flange plate of main cross-beam there is rotating lead for upper of rotating pivot standard type and arms for sprung side bearers. The passage from the front to the center part of the wagon is branched because of better layout longitudinal forces. The center section of chassis frame contains the cross brace by reason optimizing the torsional stiffness of the wagon. The material thickness 


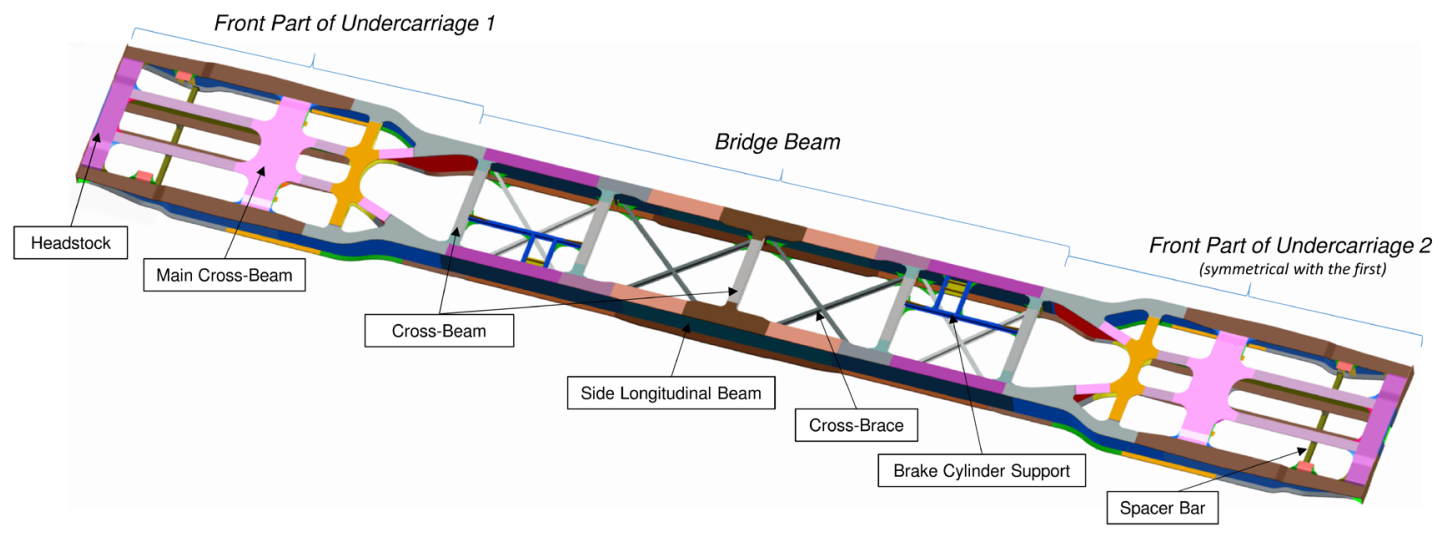

Fig. 4. Main parts of the chassis frame.

of individual structural parts has been optimized based on strength analysis simulations.

\section{Computer aided simulation analyzes}

Integral part of the development of rail vehicles are ride tests performed on test tracks and static tests on test stands. These tests are expensive and nowadays are using the modern computer technologies that can simulate riding a vehicle/train on the track and detect selected parameters $[2,3]$.

For the proposed wagon were performed following simulation analyzes:

- Static evaluation:

- wagon torsional stiffness,

- max. vertical load forces,

- wagon rising on one side,

- all wagon rising,

- longitudinal forces,

- load combination.

- Dynamic evaluation:

- modal analysis,

- simulation of the ride through the S-curve,

- geometric characteristics of wheelset and track,

- acceleration, wheel forces, guiding forces and safety against derailment.
Investigated construction was subjected to static structural analysis (program ANSYS) based on the standards $[4,5]$. On the basis of the 3D model of chassis frame was created calculation model which characteristics are shown in Fig. 5.

The task of structural analysis was to simulate behaviours of stresses and deformations in the proposed construction loaded maximum vertical forces.

The simulation analysis shows that the greatest deflection investigated structures (middle of the wagon) will be $29,92 \mathrm{~mm}$. The report ERRI B12/RP17 states that the maximum deflection of the chassis frame must not exceed $3 \%$ of the distance between bogie pivots respectively axis of wheelsets. The results of the simulations show that the chassis frame satisfies strength conditions. For further development respectively production of this type of construction it is necessary to verify the results on the real construction on the test stand $[6,7,8]$. Behaviour of displacements and stresses is shown in Fig. 6.

The dynamics analysis was performed in accordance to the technical parameters for two track sections in Cerhenice railway test track circuit. In the first case was taken into account the track with $450 \mathrm{~m}$ radius and in

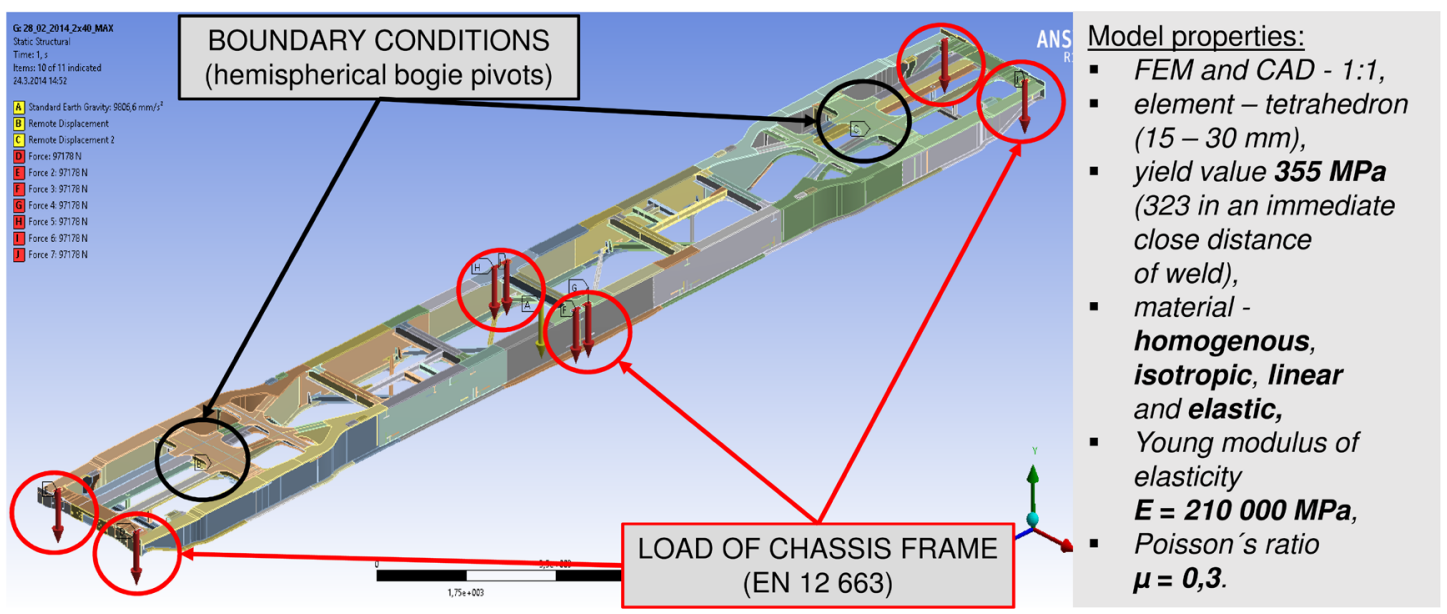

Fig. 5. Computational model - boundary conditions, loads and properties. 


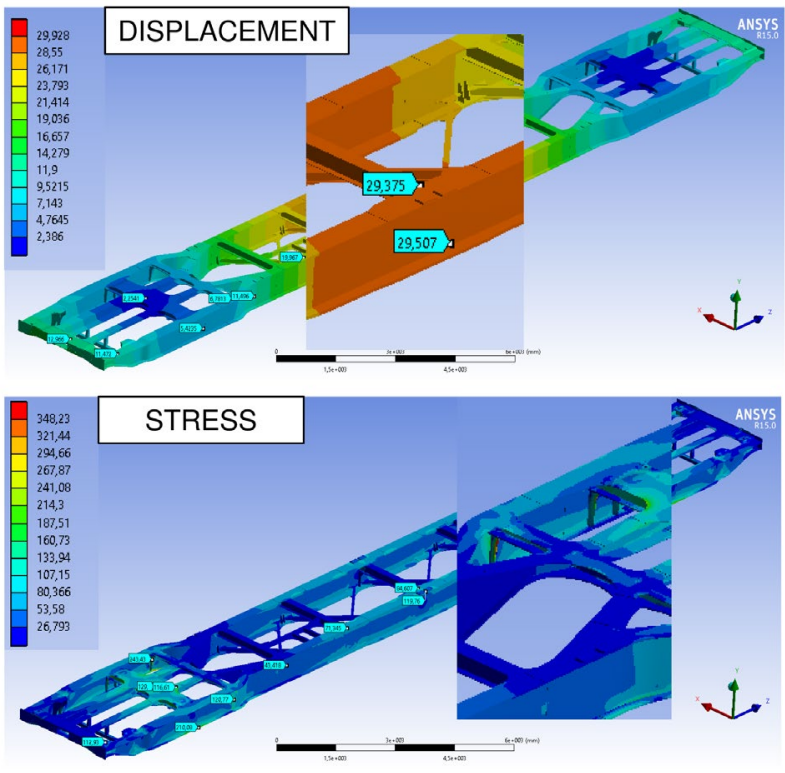

Fig. 6. Results of static simulation analysis - max. displacement and stress.

second case the right track and the velocity of $100 \mathrm{~km} / \mathrm{h}$.

The geometric characteristics $[9,10,11]$ of railway wheelset and track (Equivalent conicity and Delta-R function) were evaluated for the profiles contact couples S1002 for wheel, UIC60 and R65 rail with inclinations of 1:20 and 1:40 (right track) and for the profiles contact couples S1002 for wheel, S49 rail with inclinations of 1:20 and 1:40 (radius R450 m).

The geometric characteristics analysis for both cases was completed with the Equivalent conicity and Delta $\mathrm{R}$ function characteristics (Fig. 7) set for different gauges values (in the interval of 1432-1448 mm).

For both analysis the accelerations, wheel vertical forces and leading lateral forces values, from them the derailment criterion (safety against derailment) was evaluated.
In both cases, the safety against derailment values, were in the interval of safe operation.

With this research and development subjects deals other publications too $[12,13,14,15]$.

\section{Conclusion}

It is estimated that this wagon will be a sustainable wagon that will be able to offer the same or even more capacity and utilize less resources and energy than current wagons for intermodal transport.

The analysis of the intermodal traffic has enabled to carry a simulation in which wagon capacity performance has been assessed. The primary results speak for an increase of capacity due to wagon use of about $10 \%$ in comparison to a realistic reference case. This capacity increase is mainly produced by a better arrangement of containers and by reduction of deadweight of the wagon. When it comes to energy consumption wagon could save up to $18 \%$ of the energy necessary to transport a units. This is mostly due to an improvement of the loading factor that enables a better compression of the containers, fewer gaps, a reduced number of axles and a lighter tare per units.

Main advantages over existing design are:

- lower loading plane $=$ transport of containers and swap bodies all dimensions in kinematic gauge G1 (including HiCube containers and swap bodies with a wide of up to $2600 \mathrm{~mm}$ ),

- distance between pivots to $18000 \mathrm{~mm}=$ no special permissions.

Due to the reduced amount of axles, for same or even more units capacity, wagon will bring about important savings in maintenance and very importantly, it will reduce the noise emissions per train.

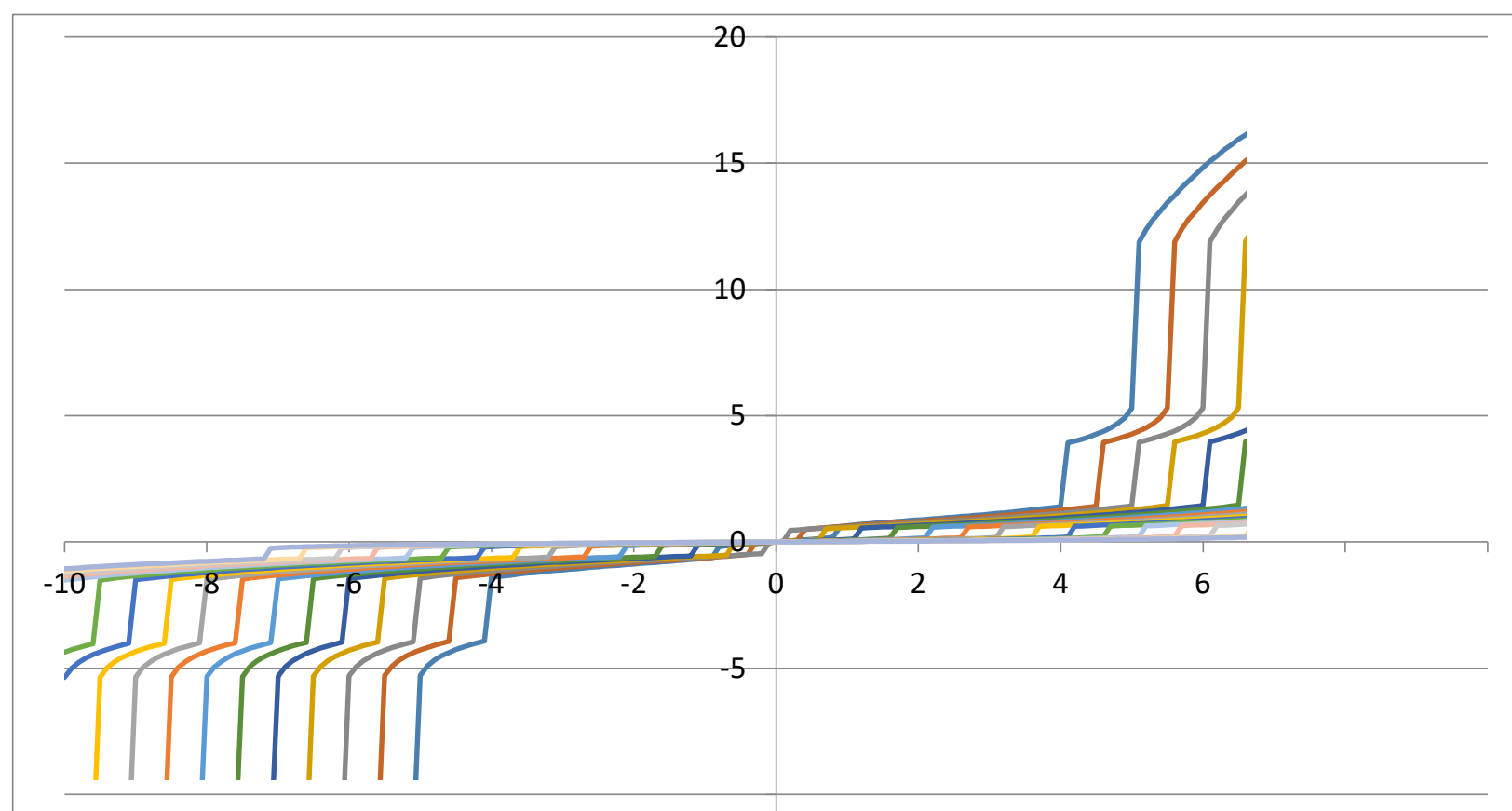

Fig. 7. Delta R function S1002/R65/1:40/gauge 1432 - 1448. 
This work was supported by the Cultural and Educational Grant Agency of the Ministry of Education of the Slovak Republic in project No. KEGA 077ŽU4/2017: Modernization of the Vehicles and engines study program. The work was also supported by the project No. APVV-0842-11: Equivalent railway operation load simulator on the roller rig and VEGA No. 1/0558/18: Research of the interaction of a braked railway wheelset and track in simulated operational conditions of a vehicle running in a track on the test stand.

\section{Research-Educational Center of Rail Vehicles (VVCKV)}

\section{References}

1. P. Fabián, J. Gerlici, J. Mašek, P. Márton, Versatile, efficient and long wagon for intermodal transport in Europe. Communications: scientific letters of the University of Žilina. ISSN 1335-4205. Vol. 15, No. 2, pp. 118-123 (2013).

2. J. Dižo, J. Harušinec, M. Blatnický, Structural analysis of a modified freight wagon bogie frame. MATEC Web of Conferences. ISSN 2261-236X. Vol. 134 (2017).

3. J. Dižo, S. Steišunas, M. Blatnický, Vibration analysis of a coach with the wheel-flat due to suspension parameters changes. Procedia Engineering, ISSN 1877-7058. Vol. 192, pp. 107112 (2017).

4. EN 12 663-2: Railway applications. Structural requirements of railway vehicle bodies. Part 2: Freight wagons. European Committee for Standardization (2011).

5. ERRI B12/RP17, No. 8: Programme of Stresses to be carried out on Wagons with Steel Underframe and Body Structure. European Rail Research Institute (1996).

6. J. Gerlici, T. Lack, Modified HHT method for vehicle vibration analysis in time domain utilisation. Applied mechanics and materials. ISSN 1660-9336. Vol. 486, pp. 396-405 (2014).
7. J. Gerlici, T. Lack, Rail vehicles brake components test bench utilisation. Applied mechanics and materials. ISSN 1660-9336. Vol. 486, pp. 379-386 (2014).

8. J. Gerlici, T. Lack, J. Harušinec, Realistic simulation of railway operation on the RAILBCOT test stand. Applied mechanics and materials. ISSN 1660-9336. Vol. 486, pp. 387-395 (2014).

9. T. Lack, J. Gerlici, A modified strip method to speed up the calculation of normal stress between wheel and rail. In Applied mechanics and materials. ISSN 1660-9336. Vol. 486, pp. 359-370 (2014).

10. T. Lack, J. Gerlici, A modified strip method to speed up the tangential stress between wheel and rail calculation. Applied mechanics and materials. ISSN 1660-9336. Vol. 486, pp. 371-378 (2014).

11. J. Gerlici, T. Lack, Railway wheel and rail head profiles development based on the geometric characteristics shapes. Wear: An international journal on the science and technology of friction, lubrication and wear. ISSN 0043-1648. Vol. 271, No. 1-2, Sp. iss., pp. 246-258 (2011).

12. J. Gerlici, T. Lack, Contact geometry influence on the rail / wheel surface stress distribution. Procedia Engineering. ISSN 1877-7058. Vol. 2, Iss. 1, pp. 2249-2257 (2010).

13. T. Lack, J. Gerlici, Railway wheel and rail roughness analysis. Communications: scientific letters of the University of Žilina. ISSN 1335-4205. Vol. 11, No. 2, pp. 41-48 (2009).

14. V. Hauser, et. al., Proposal of a steering mechanism for tram bogie with three axle boxes. Procedia Engineering. ISSN 1877-7058. Vol. 192, pp. 289294 (2017).

15. V. Hauser, et. al., Impact of three axle boxes bogie to the tram behavior when passing curved track. Procedia Engineering, ISSN 1877-7058. Vol. 192, pp. 295-300 (2017). 